\title{
A naturalização da diferença
}

\author{
The naturalization of difference \\ Monica Pimenta Velloso \\ Doutora em história social \\ Fundação Casa de Rui Barbosa \\ Rua São Clemente, 134 \\ 22260-000 — Rio de Janeiro - RJ Brasil
}

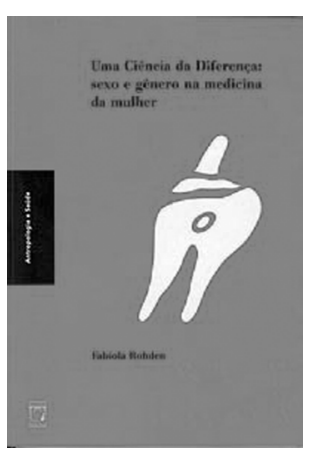

Fabíola Rohden Uma ciência da diferença: sexo e gênero na medicina da mulber

Rio de Janeiro, 2001, 224p.

Editora Fiocruz,
A construção social da sexualidade vem sendo inventariada pelos mais diversos campos de conhecimento, mas, sem dúvida, é no discurso médico que vai encontrar um dos seus filões mais ricos de análise. Na virada do século XIX para o XX, a onda transformadora advinda da aceleração do processo urbano industrial, entre as suas inúmeras conseqüências, propiciou o ingresso da mulher no mercado de trabalho e a elaboração do ideário feminista, descortinando-se, assim, novas possibilidades de relacionamento entre os gêneros.

Nesse cenário, tão profundamente marcado pelos ventos da mudança, impunha-se a necessidade de repensar e demarcar os papéis sociais.

Os médicos, na condição de 'homens de ciência', se auto-elegem como a instância legítima e competente para fazê-lo. Munidos de um saber considerado redentor, buscam garantir as bases da diferença entre homens e mulheres. É nesse contexto que a ginecologia, surgindo como nova especialização da medicina, será contemplada como a 'ciência da diferença'. Esse é o fio condutor da reflexão desenvolvida por Fabíola Rohden em Uma ciência da diferença: sexo e gênero na medicina da mulher.

Como o discurso médico vai construir a idéia da 'diferença sexual' no intuito de manter, reelaborar e reafirmar a hierarquia entre os gêneros? É com base nessa indagação que a autora estrutura o seu trabalho, entrecruzando harmoniosamente as perspectivas da antropóloga e da historiadora. Inspirando-se no que denomina uma situação etnográfica privilegiada (p. 197), a autora analisa o caso do médico Abel Parente, membro fundador da Sociedade de Medicina e Cirurgia do Rio de Janeiro. Parente destacou-se na comunidade acadêmica ao defender uma tese considerada revolucionária e, de certa forma, imoral para o pensamento da época. A proposta da esterilização feminina era percebida então como ameaça social capaz de desestabilizar os fundamentos da moral e da ordem burguesa.

O trabalho atento e cuidadoso da historiadora destaca-se, sobretudo, na análise documental, empreendida com base nos arquivos da Faculdade de Medicina do Rio de Janeiro, que contempla, especificamente, as teses sobre ginecologia produzidas no período compreendido entre 1833 e 1940.

Nesse 'discurso da diferença' uma das idéias que, a meu ver, merece especial destaque é aquela que faz aparecer o gênero colado à idéia de sexo. Assim, a mulher é incessantemente 'naturalizada', ao contrário do homem, de modo geral associado ao domínio da cultura, da ação e do pensamento. É a partir desse viés - instituidor da naturalização 
da diferença - que a autora mapeia o discurso médico da época, na perspectiva de contrastá-lo com algumas de suas vozes dissonantes, incorporadas, no caso, por Abel Parente e os que o apoiaram.

Em sua pesquisa, Fabíola Rodhen elege o corpo feminino como objeto de investigação historiográfica, mostrando que é sobre ele que se articula o discurso médico destinado a referendar a diferença. Pensa, portanto, o corpo na sua historicidade, o que significa analisá-lo não apenas como lugar da definição sexual, mas sobretudo da demonstração das distinções e das diferenças que o estigmatizam e o excluem. O corpo é focalizado na sua multiplicidade e complexidade, definindose como constructo cultural incessantemente reinventado.

O conjunto da obra resulta equilibrado, distribuindo-se pelos capítulos uma densa discussão acerca da emancipação feminina, da institucionalização das especialidades médicas referentes à mulher e do caráter normativo e oficial do discurso médico. O trabalho culmina com a análise do caso concreto do médico Abel Parente, acusado, entre outras coisas, de desviar a mulher do seu destino 'natural', tendo ocasionado a loucura de algumas das suas pacientes.

No primeiro capítulo, respaldando-se em algumas análises clássicas como as de Peter Gay ( $A$ educação dos sentidos) e de Norbert Elias (O processo civilizador), a autora mostra o século XIX como um marco na construção social do feminino, contrastando com o século anterior, pautado pela masculinidade. Nesse contexto, o médico torna-se voz autorizada e onipresente na sociedade, pretendendo intervir nos seus mais variados domínios. A paciente deixaria de "seguir conselhos, passando a obedecer ordens" (p. 24).

Nas representações médicas, o corpo e a alma femininos passam a ser condicionados pelo sexo e, conseqüentemente, pela idéia de maternidade. A um corpo arredondado, volumoso e de seios generosos corresponderia um temperamento marcado pela fragilidade moral. Se o discurso médico busca escudar-se na 'ciência da mulher' para fazer frente à crescente influência do feminismo, é necessário, porém, analisar mais cuidadosamente a questão.

Eis o aspecto importante para o qual a autora nos chama a atenção. Atenta às ciladas da 'teoria da vitimização' que marca os primeiros estudos de gênero, ela sugere um outro caminho: considerar o conjunto do campo discursivo, das práticas sociais e atores envolvidos. A partir daí, seria lícito indagar: até que ponto as mulheres não internalizariam, elas próprias, determinados comportamentos usando as teorias de acordo com os seus interesses?

No segundo capítulo, encontramos um panorama histórico cuidadoso da obstetrícia e da ginecologia no Brasil, marcado pela parceria entre a medicina e o Estado. Vale destacar especificamente a parte referente à história do ingresso das mulheres na profissão médica. No âmbito internacional, a autora mostra-nos a participação expressiva das feministas que passaram a criticar teses vigentes, como a 'fragilidade fisiológica' da mulher que colaborava para sua exclusão das funções públicas. No Brasil, essa tese também seria objeto de intenso debate entre aqueles que defendiam a emancipação feminina e os que tentavam dificultá-la, respaldando-se na argumentação da cientificidade. 
Nesse capítulo, vemos ainda como as primeiras profissionais mulheres na área médica acabaram interiorizando determinados valores dominantes. Por exemplo, o caso da primeira parteira, Mme Durocher, diplomada pela Faculdade Nacional de Medicina do Rio de Janeiro (1834), que, para transmitir confiabilidade às suas clientes, mimetizava o comportamento masculino. Em sua autobiografia, Mme Durocher observava que uma mulher atraída por "fitas, renda, enfeite de cabelo, jóia e tantas outras bugigangas" não poderia ter "precisa aptidão e constância necessária para sérios estudos de gabinete, para as observações na prática, ao lado da parturiente" (p. 82).

Na história das primeiras profissionais mulheres na área médica consta o nome de d. Pedro II como mecenas que teria custeado nos Estados Unidos os estudos de Maria Augusta Generoso Estrela, diplomada em 1879. A receptividade que teve a primeira médica a diplomar-se no Brasil, Ermelinda Lopes de Vasconcelos, em 1888, denota a associação feita entre a idéia da emancipação feminina e o ingresso do país na modernidade. Na ocasião, organizou-se uma passeata pelas principais ruas da cidade, sendo a estudante saudada por José do Patrocínio, Quintino Bocaiúva e Rui Barbosa.

Tomamos conhecimento também do conturbado cotidiano de algumas mulheres que ousaram trilhar os novos caminhos da profissionalização abertos pela medicina. Personagens que ousaram romper com as expectativas e papéis sociais que lhes circunscreviam tradicionalmente à esfera do privado, do anonimato e da invisibilidade social, conforme análise desenvolvida por Michelle Perrot em Os excluídos da história (1988).

Com base na documentação dos arquivos da Faculdade Nacional de Medicina do Rio de Janeiro, o terceiro capítulo trabalha a fundo a questão da construção das diferenças. Fabíola Rohden mostra-nos que o eixo argumentativo de toda essa trama discursiva repousa em uma idéia-chave: a da reprodução. A uma organização corporal diferenciada corresponderiam, portanto, papéis sociais diferenciados. As ciências, artes e invenções atividades de esforço intelectual - eram consideradas áreas de atuação masculina. Moldadas anatomicamente pela natureza, as mulheres deveriam direcionar os seus esforços no sentido de privilegiar as funções de gestação, parto, amamentação, cuidado dos filhos e do marido (p. 111).

Nesse sentido, a autora chama a atenção para o título de uma tese defendida por Afonso Cordeiro de Negreiros Lobato Júnior, Mulher em geral: menstruação e suas causas (1855). Para Lobato Júnior, é só no momento em que a mulher toma consciência de sua função reprodutiva que deixa de se apresentar como um 'ser equívoco', indefinido socialmente.

Nos discursos médicos analisados, a diferenciação do gênero aparece fortemente respaldada pelas teorias de Lombroso. A representação da 'mulher histérica', associada à loucura e à criminalidade, funcionava como argumento recorrente para fundamentar a intervenção e normalização médicas. Consideradas 'moralmente irresponsáveis', as mulheres, segundo algumas teses da medicina, demandavam proteção e cuidados especiais que iam desde a criação de asilos e patronatos à formação de comissões médicas para julgá-las, no caso de terem cometido crimes.

Após discutir exaustivamente a constituição da diferença feminina centrada na ginecologia, Fabíola Rodhen apresenta-nos, no quarto capítulo, o caso do médico Abel Parente. O desenvolvimento do seu trabalho, até alcançar esse capítulo, lembra o recurso ao método 
indiciário do 'historiador-detetive', sugerido por Carlo Ginzburg em Mitos, emblemas e sinais (1990).

Para Ginzbug, o modelo cognitivo indiciário que serviria de base interpretativa para campos de conhecimento tão distintos entre si, como a psicanálise, a historiografia da arte e a criminologia se estrutura com base no deciframento de pistas e de sinais. Cercado o campo das 'evidências', a autora parte no encalço do caso concreto: o do médico Abel Parente. Como, por quê, baseada em que a tese da 'esterilização feminina provisória', defendida por Parente, fora objeto de tantas e tamanhas controvérsias? Como conseguira envolver e mobilizar tantas instituições e pessoas? Afinal de contas, em que ela destoava e, sobretudo, contrariava o saber médico da época?

Arrolando cuidadosamente os discursos acusativos contra o médico Abel Parente, a autora reforça sua tese inicial: a da naturalização das diferenças entre os gêneros. Apresentando-se como os defensores da moralidade pública, os médicos acusavam o colega Parente de estar cometendo um crime de lesa-pátria ao praticar a esterilização. Confundia-se, propositadamente, a prática da esterilização com a do aborto. Se a sexualidade feminina era assunto que não pertencia ao poder decisório das mulheres, mas ao dos médicos e dos maridos, a esterilização passava a ser considerada crime contra a natureza. Argumentava-se, assim, que a esterilização provocava o descontrole da sexualidade, advindo daí a loucura, a imoralidade (prostituição) e a crise da instituição familiar. Entrando em conflito com sua verdadeira natureza e predestinação - a procriação - a mulher provocava não só a sua desordem interna corporal, mas a desordem social.

Esses argumentos da tese do dr. Públio de Mello, da Sociedade de Higiene do Brasil, vão desencadear o debate público. Na defesa, a autora detém-se na análise da obra do dr. Francisco de Castro, da Diretoria Sanitária, Abel Parente do ponto de vista do direito criminal, da moral pública e da medicina clínica (1893). Aspecto digno de nota é a própria redefinição que se opera em torno do conceito de imoralidade. Não seria o controle da sexualidade e o livre-arbítrio do casal mais moral do que a multiplicação indefinida da prole, abandonando-se esta aos cuidados da sociedade? A indagação, envolvendo sobretudo a idéia da mulher como sujeito das decisões, era revolucionária para os padrões morais da época.

A polêmica vai aumentar, ao longo da primeira década do 1900, abrangendo um amplo e diversificado leque de questões, que passam pela ética, direito, criminalidade, publicidade, feminismo, sexualidade, estética, natalidade, malthusianismo e eugenia, remetendo ao grande debate em questão: a distinção entre a esfera da natureza e da cultura. Por aí, tem-se a reconstituição de um quadro fértil e extremamente rico do debate das idéias sociais que se fizeram presentes no campo da medicina e da saúde pública. Tomando como foco de análise o microcosmo da ginecologia, a autora consegue mapear, com acuidade, as principais linhas do debate científico da época, estruturado em torno da classificação e hierarquização do conhecimento e dos gêneros.

Um dos méritos do trabalho de Fabíola Rodhen é o de ressaltar os aspectos múltiplos e contraditórios que vazam não só do discurso 
médico, mas também daquele produzido pelas mulheres escritoras referente à própria representação do feminino. A plasticidade, por assim dizer, que permeia tais discursos reflete a multiplicidade de interesses em jogo: se, de um lado, legitimava-se a diferença homem-mulher com base na natureza biológica, de outro, mostravam-se os fundamentos sociais passíveis de moldar e de construir essas diferenças. Roy Porter em a 'História do corpo', artigo publicado em A escrita da história (1992), chama a atenção para o fato ao ressaltar o caráter complexo das relações corpo-mente, sendo o corpo mediado por sistemas de sinais culturais. Observa que a distribuição da função e da responsabilidade entre corpo e mente difere de acordo com o século, a classe, as circunstâncias e a cultura, possuindo as sociedades uma pluralidade de significados concorrentes.

Resgatando a leitura foucaultiana sobre a sexualidade, a autora reforça o papel da instabilidade e da fluidez das categorias como forma de legitimar as diferenças (de classes e de etnias) entre as mulheres. A análise do caso do médico Abel Parente, empreendida por Fabíola Rodhen, reforça a centralidade da historicidade, revelando-se essa através do caráter cambiante e fluido das fronteiras que organizam o mundo social. Denota-se claramente, aí, como os limites, as atribuições e as hierarquias dos papéis sexuais são constantemente redefinidos em função das questões colocadas pela dinâmica social. Inspirandose no panorama mutante da virada do século XIX para o XX, a autora capta, com sensibilidade e profundo espírito de análise, um desses momentos singulares em que a mudança impõe-se como força reestruturadora, buscando conferir novos sentidos e inteligibilidade à dinâmica história do cotidiano.

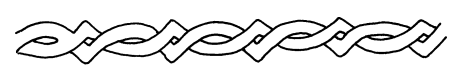

